Submitted to Meta-Psychology. Withdrawn due to lack of reviewers. Currently submitted to Journal of Integrative Neuroscience in process of revision.

\title{
Association between DRD2/ANKK1 TaqIA allele status and striatal dopamine D2/3 receptor availability in alcohol use disorder
}

Authors/affiliations:

G. Spitta (ORCID: $0000-0001-9222-3591)^{1}$, L.E. Fliedner ${ }^{1}$, T. Gleich ${ }^{1}$, T. Zindler (ORCID: $0000-0001-7042-$ $0578)^{2}$, M. Sebold (ORCID: $\left.0000-0002-6006-3201\right)^{1}$, R. Buchert (ORCID: 0000-0002-0945-0724) ${ }^{3}$, A. Heinz ${ }^{1}$, J. Gallinat ${ }^{4}$, E. Friedel (ORCID: $\left.0000-0001-8859-4234\right)^{1,5}$

${ }^{1}$ Charité Universitätsmedizin Berlin, corporate member of Freie Universität Berlin, Humboldt-Universität zu Berlin, and Berlin Institute of Health, Charité Campus Mitte (CCM), Berlin, Germany

${ }^{2}$ Department of Psychiatry, Social Psychiatry and Psychotherapy, Hannover Medical School, Hannover, Germany

${ }^{3}$ Department of Diagnostic and Interventional Radiology and Nuclear Medicine, University Medical Center Hamburg-Eppendorf, Hamburg, Germany

${ }^{4}$ Department of Psychiatry and Psychotherapy, University Medical Center HamburgEppendorf (UKE), Hamburg, Germany

${ }^{5}$ Berlin Institute of Health (BIH), Berlin, Germany

\section{Abstract}

The association between blunted dopaminergic neurotransmission and alcohol use disorder (AUD) is well-known. In particular, the impairment of postsynaptic dopamine 2 and 3 receptors (DRD2/3) in the ventral and dorsal striatum during the development and maintenance of alcohol addiction has been investigated in several positron emission tomography (PET) studies. However, it is unclear whether these changes are the result of adaptation or genetic predisposition. Here we investigated the association between DRD2/ankyrin repeat and kinase domain-containing 1 (ANKK1) TaqIA allele (rs1800497) status and striatal DRD2/3 availability measured by ${ }^{18} \mathrm{~F}$-fallypride PET in 13 AUD patients and 17 sexmatched healthy controls. Age and smoking status were included as covariates. Contrary to our expectations, TaqIA allele status was not associated with striatal DRD2/3 availability in either group and there was no significant difference between groups, possibly due to the relatively small sample size $(\mathrm{N}=30)$. Nonetheless, this is the first in vivo study investigating the relationship between dopamine receptor availability and genetic factors in AUD. The pitfalls of assessing such relationships in a relatively small sample are discussed.

Key words: alcohol dependence; dopamine D2 and D3 receptor availability; DRD2/ANKK1 TaqIA allele status; ${ }^{18} \mathrm{~F}$-fallypride PET

\section{Introduction}


Alcohol use disorder (AUD) is a complex and chronic disorder with high costs for society. The pathogenesis of AUD involves an interplay of social, individual, and biological factors; approximately $50 \%$ of the etiology of alcohol dependence is attributed to genetic influence (Dick \& Bierut, 2006).

Chronic alcohol intake is associated with lower dopamine receptor availability. In particular, reduced availability of dopamine D2 and D3 receptors (DRD2 and DRD3, respectively) in the striatum of patients with alcohol dependence compared to healthy controls (HCs) has been demonstrated by several positron emission tomography (PET) studies (Erritzoe et al., 2014; Gleich et al., 2020; Heinz et al., 2004, 2005; Hietala et al., 1994; Rominger et al., 2012; Volkow et al., 2002, 2007) and described in recent reviews (Alexandre et al., 2019; Kamp et al., 2018). However, it is unclear whether these changes reflect neuroadaptations to excess acute striatal dopamine release during regular substance use or are the result of genetic predisposition for substance use disorder. Several potential contributing genetic factors have been discussed in the literature. DRD2/ankyrin repeat and kinase domain-containing 1 (ANKK1) TaqIA allele status ( $r$ 1800497) has been linked to alcohol dependence in several studies (Blum et al., 1990, 1991; Mignini et al., 2012; Neiswanger et al., 1995), although the effect size of the DRD2 A1 allele was found to be small (Berggren et al., 2006).

Inconsistencies in published results have cast doubt on the functional relevance of the DRD2/ANKK1 TaqIA allele in AUD, as there is limited evidence that rs1800497 affects DRD2 function. A recent meta-analysis of 62 studies including 16294 participants found that the positive association between DRD2 and alcoholism was due to low allele frequencies in control subjects rather than changes in DRD2 gene expression (Jung et al., 2019). On the other hand, single nucleotide polymorphism (SNP) of the DRD2/ANKK1 (rs1800497) Taql allele was shown to be linked to reduced striatal DRD2/3 availability (Gluskin \& Mickey, 2016), which has also been reported in obesity, schizophrenia, and schizoaffective disorder (Eisenstein et al., 2016). Additionally, TaqIA allele status was found to be associated with higher DRD2/3 availability in patients with major depressive disorder and lower availability in HCs (Savitz et al., 2013).

To date there have been no in vivo studies investigating DR availability and DRD2/ANKK1 TaqIA allele status in AUD, except for a postmortem study reporting a link between the binding characteristics of DRD2 in the cerebral cortex and AUD (Noble et al., 1991). We previously showed that dorsostriatal DRD2/3 availability was reduced in AUD patients and individuals at high risk for developing AUD compared to HCs (Gleich et al., 2020).

The present study investigated DRD2/ANKK1 TaqIA allele status as well as striatal DRD2/3 availability by ${ }^{18} \mathrm{~F}$-fallypride PET in patients with AUD in order to evaluate their contributions to alcohol dependence.

\section{Materials and Methods}

This study is part of a multicenter project investigating behavioral, genetic, and neuroimaging changes associated with reward-based learning and its relevance to the maintenance of alcohol dependence (www.lead-studie.de; clinical trial number NCT01679145). The study was approved by the local ethics committee (Charité - Universitätsmedizin Berlin; EA1/245/11) and all subjects gave written, informed consent before participating. Recruitment took place between 2014 and 2016. The main objective was to investigate striatal DRD2/3 availability by PET as well as glutamate level in the prefrontal cortex by magnetic resonance imaging (MRI) in patients with or at high risk of developing alcohol dependence, as well as in HCs. As we also 
planned to explore the neurochemical changes in AUD with potential predisposing genetic factors, blood samples were collected from the study participants for biochemical analysis and genotyping. The specific research question of the association between DRD2/ANKK1 (rs1800497) Taql allele status and DRD2/3 availability was evaluated in a post hoc analysis. The assessed samples constituted a subsample of the abovementioned study cohort for which PET and genetic data were available.

\section{Sample}

The sample consisted of $17 \mathrm{HCs}$ and 13 detoxified, abstinent patients diagnosed with AUD. Subjects were matched for age, sex, education, handedness, and smoking status (Table 1). AUD patients were recruited from hospitals in Berlin and had met Diagnostic and Statistical Manual for Mental Disorders, 4th Edition (DSM-IV) criteria for AUD for at least 3 years (American Psychiatric Association, 2000) prior to the start of the study. The patients were diagnosed at the participating institutions by a trained clinician and their diagnosis was later confirmed with the Composite International Diagnostic Interview (CIDI) (Jacobi et al., 2013; Wittchen et al., 1998) during testing. AUD patients had been abstinent for at least $72 \mathrm{~h}$ when they were tested, had mild withdrawal symptoms (Clinical Institute Withdrawal Assessment for Alcohol score <3), and were free of any psychotropic medication for at least 4 half-lives (Sullivan et al., 1989). HCs were recruited via local online platforms and did not meet DSM-IV criteria for AUD in the standardized telephone screening, which was confirmed with the CIDI.

All study participants with any other current substance use or dependence apart from alcohol and nicotine were excluded from the study. Subjects were instructed not to drink any alcoholic beverages in the $24 \mathrm{~h}$ before PET scanning. Compliance was verified by urine screening and breath alcohol tests. Participants with any contraindications for MRI, current pregnancy or nursing, or any neurologic or major psychiatric disorder according to DSM-IV criteria were also excluded from the study (American Psychiatric Association, 2000; Anton et al., 1995; Kivlahan et al., 1989).

The study consisted of 3 separate testing sessions. In the first session, participants were asked to complete clinical questionnaires such as the Alcohol Dependence Scale or Obsessive Compulsive Drinking Scale, and underwent blood sampling for the genetic analyses (Anton, 1999, 2000; Anton et al., 1995; Kivlahan et al., 1989). MRI and PET scanning took place in the second and third sessions, respectively.

Table 1. Sample characteristics ( $N=29)$

\begin{tabular}{|c|c|c|c|}
\hline \multirow[t]{2}{*}{ Variable } & \multicolumn{2}{|c|}{ Group } & \multirow{2}{*}{$\begin{array}{l}p \text { Value for } \\
\text { test statistic }\end{array}$} \\
\hline & AUD $(n=12)$ & $\mathrm{HC}(n=17)$ & \\
\hline \multicolumn{4}{|l|}{ Demographic characteristics } \\
\hline Sex, no. of females/males & $1 / 11$ & $2 / 15$ & $0.77^{c}$ \\
\hline Education, years & $15.1(3.6)$ & $14.8(3.3)^{\S}$ & $0.62^{a}$ \\
\hline Age, years & $44.5(9.3)$ & $45.4(8.9)$ & $0.80^{b}$ \\
\hline Smoker, \% & 83 & 59 & $0.16^{c}$ \\
\hline \multicolumn{4}{|l|}{ Clinical characteristics } \\
\hline Duration of abstinence, days & $34.4(23.6)$ & - & - \\
\hline Severity of alcohol dependence ${ }^{+}$ & $17.7(5.8)$ & $3.5(3.8)$ & $<0.0001^{* a}$ \\
\hline Craving $^{\ddagger}$ & $13.7(8.0)^{\S}$ & $3.8(3.3)$ & $<0.0001^{* a}$ \\
\hline
\end{tabular}

Data are shown as mean (standard deviation) unless otherwise indicated. 
${ }^{\dagger}$ Determined using the Alcohol Dependence Scale (Kivlahan et al., 1989).

${ }^{\ddagger}$ Determined using the Obsessive Compulsive Drinking Scale (Anton et al., 1995; Anton, 2000).

$\S$ Information was not available for 1 subject.

*Significant difference; ${ }^{a}$ Wilcoxon rank-sum test; ${ }^{b}$ test; ${ }^{c} \chi{ }^{2}$ test.

Abbreviations: AUD, alcohol use disorder; HC, healthy control.

\section{DNA extraction and genotyping}

DNA was semi-automatically extracted from whole blood with the Chemagen Magnetic Separation Module (Perkin Elmer, Boston, MA, USA). Genotyping was performed with the Infinium Psych Array Bead Chip (Illumina, San Diego, CA, USA). Three subjects were excluded from the final sample as outliers in the genome-wide association study. We examined the status of the rs1800497 SNP, which is also known as the TaqIA polymorphism of the DRD2 gene. The minor allele is a C-to-T substitution (i.e., A1, rs1800497[T)) that is associated with a reduced number of dopamine binding sites in the brain and is thought to play a role in alcoholism, smoking, and certain neuropsychiatric disorders (Jung et al., 2019). As there are 2 different allele types, 3 genotypes were possible ( $A 1 / A 1, A 1 / A 0$, and $A 0 / A 0)$. Because of the very limited prevalence of $A 1 / A 1$ in the $H C(n=0)$ and AUD $(n=1)$ groups, we pooled $A 1 / A 1$, $A 1 / A 0$, and $A 1$ into a single group. The allele frequencies are shown in Table 2.

\section{MRI and PET data acquisition and processing}

For MRI, T1-weighted images were acquired using a 3 Tesla Verio scanner (Siemens, Munich, Germany) with a magnetization prepared rapid gradient echo (MPRAGE) sequence (isotropic resolution $=1.0 \mathrm{~mm}$, repetition time $=2.3 \mathrm{~s}$, echo time $=3.03 \mathrm{~ms}$, inversion time $=900 \mathrm{~ms}$, and flip angle $=9^{\circ}$ ).

PET scanning was performed using a time-of-flight PET/computed tomography (CT) system (Gemini TF 16; Philips Medical Systems, Amsterdam, The Netherlands) (Surti et al., 2007). Dynamic PET imaging was started simultaneously with intravenous injection of ${ }^{18} \mathrm{~F}$ fallypride (Mukherjee et al., 1995; Slifstein et al., 2004). Data were acquired over $4 \mathrm{~h}$ in 3 blocks with breaks in between. A low-dose CT scan for attenuation correction was performed before each block (Slifstein et al., 2010). PET images were reconstructed using the iterative line of response-row action maximum likelihood algorithm of the scanner software with default parameter settings ( 3 iterations, 33 subsets, and "normal" relaxation). Head motion during the PET acquisition was corrected frame-by-frame using the realign tool of the Statistical Parametric Mapping software package (SPM, 2017). Thereafter, all PET frames were coregistered to each subject's MPRAGE MRI.

The 2-step simplified reference tissue method was used to obtain voxel-by-voxel parametric maps of the nondisplaceable binding potential $\left(\mathrm{BP}_{\mathrm{ND}}\right)$ of ${ }^{18} \mathrm{~F}$-fallypride. This method reduces statistical noise using a global rate constant of tracer clearance from the reference region $\left(\mathrm{Wu} \&\right.$ Carson, 2002). $\mathrm{BP}_{\mathrm{ND}}$ estimates the ratio of $\mathrm{DRD} 2 / 3$-bound ${ }^{18} \mathrm{~F}$ fallypride to nondisplaceable ${ }^{18} \mathrm{~F}$-fallypride at equilibrium (Innis et al., 2007). The superior longitudinal fasciculus as defined by Johns Hopkins University Laboratory of Brain Anatomical MRI (Hua et al., 2008) was used as a reference region to maximize the statistical power (Ishibashi et al., 2013); the cerebellum was considered unsuitable as a reference region given the cerebellar atrophy that occurs in AUD (Beck et al., 2012).

Each subject's T1 images and BP $P_{N D}$ map were normalized to Montreal Neurological Institute (MNI) anatomic space using the unified segmentation approach (Ashburner \& Friston, 2005). We used the limbic, associative, and sensorimotor striatum as regions-of- 
interest (ROIs) predefined in MNI space (Martinez et al., 2003; Mawlawi et al., 2001). The $\mathrm{BP}_{\mathrm{ND}}$ for each $\mathrm{ROI}$ was averaged between the left and right hemispheres to reduce the number of comparisons for primary analyses and because we did not have a priori hypotheses about laterality effects. We included age and smoking status as covariates in our analyses as both of these variables were shown to be independently associated with altered dopamine receptor availability (Fehr et al., 2008; Rominger et al., 2012). One AUD subject was excluded from further analysis due to extremely low means $(m=0)$ of $18 \mathrm{~F}$-fallypride $B P_{N D}$

\section{Statistical analysis}

We used R (R Core Team, 2012) and Ime4 (Bates, Maechler \& Bolker, 2012) to perform linear mixed effects analyses of the relationship between SNP status and DRD2/3 availability across prespecified striatal regions. We entered phenotype (AUD patients vs HCs) and SNP status (risk SNP vs no risk SNP) into the model as fixed effects; intercepts for subjects and brain site were entered as random effects. Visual inspection of residual plots did not reveal any obvious deviations from homoscedasticity or normality. The $p$ values were obtained by likelihood ratio tests of the full model with vs without the effect in question (maximum likelihood). DRD2/ANKK1TaqIA genotype distribution did not significantly differ from HardyWeinberg equilibrium $\left(p>0.05, \chi^{2}=0.723, d f=1\right)$.

\section{Results}

Means and standard deviations of ${ }^{18} \mathrm{~F}$-fallypride $\mathrm{BP}$ ND for all group combinations are shown in Table 2. The data structures of the 3 ROls are displayed as boxplots in Figure 1.

Table 2. Means and standard deviations of ${ }^{18} \mathrm{~F}$-fallypride $\mathrm{BP}_{\mathrm{ND}}$

\begin{tabular}{lccc}
\hline & Associative striatum & Limbic striatum & Sensomotor striatum \\
\hline HC-A- $(n=7)$ & $24.58(2.77)$ & $24.39(1.85)$ & $30.75(2.02)$ \\
HC-A+ $(n=10)$ & $24.33(3.18)$ & $24.56(2.84)$ & $29.03(2.55)$ \\
AUD-A- $(n=8)^{b}$ & $19.74(3.90)$ & $22.66(2.06)$ & $25.24(2.92)$ \\
AUD-A+ $(n=4)$ & $22.56(1.08)$ & $23.55(1.61)$ & $27.57(0.51)$ \\
\hline
\end{tabular}

Data are shown as mean (standard deviation).

Abbreviations: AUD, alcohol-use disorder; $A-$, no risk allele; $A+$, at least 1 risk allele; $\mathrm{HC}$, healthy control.

${ }^{b}$ One AUD subject was excluded for extremely low means $(m=0)$ of ${ }^{18} \mathrm{~F}$-fallypride BPND in the limbic striatum 


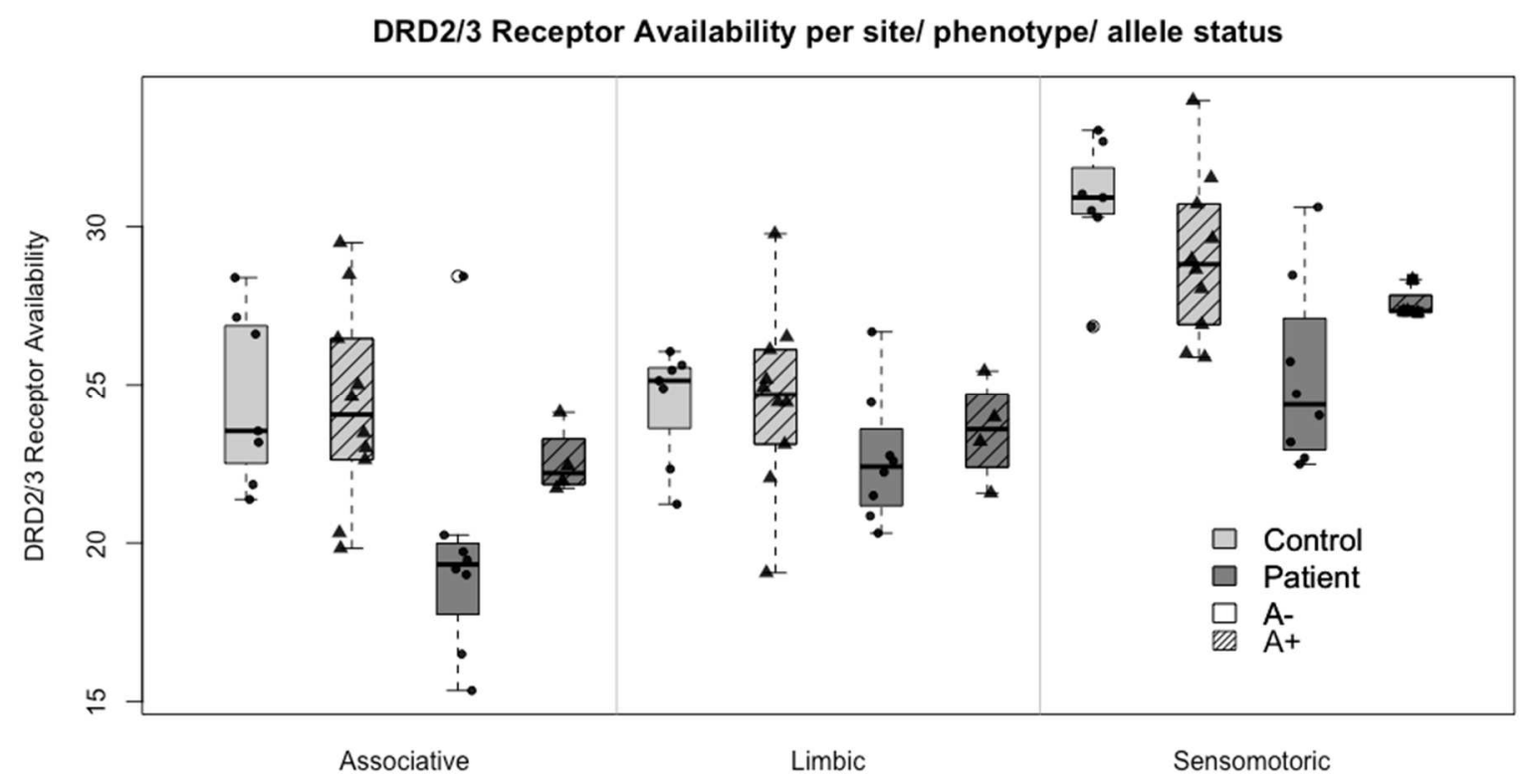

Figure 1. Boxplots of DRD2/3 availability per site in the 3 different ROIs (associative, sensorimotor, and limbic striatum) according to phenotype and allele status.

In the basic model (receptor availability $~ 1+$ brain site + phenotype [HC/AUD] + [1 | ID]), $61 \%$ (interclass correlation coefficient) of the total variance in receptor availability was accounted for by person clustering. There was a significant improvement in model fit with a nested data structure $\left(\operatorname{logLik} \Delta \chi^{2}[1]=31.8, p<0.0001\right)$; both the Akaike information criterion (AIC) and Bayesian information criterion (BIC) were smaller with this model (AIC: 446.26 vs 416.46; BIC: 456.13 vs. 428.79 ).

As expected, we found a significant main effect of phenotype status ( $0=\mathrm{HCs} ; 1=A U D$ patients) $\left(\chi^{2}[1]=11.49, p<0.001\right)$, indicating that $B P_{N D}$ across brain regions was lower in AUD patients compared to controls. Including DRD2/ANKK1 TaqIA allele status did not significantly improve model fit $\left(\chi^{2}{ }_{[1]}=0.276, p=0.5996\right)$, indicating that the DRD2/ANKK1 TaqIA allele does not predict $\mathrm{BP}_{\mathrm{ND}}$ either alone or through interaction with group.

\section{Discussion}

The results of this study demonstrate that DRD2/3 availability is reduced in the associative, sensorimotor, and limbic striatum of AUD patients compared to HCs. This supports our hypothesis and is in line with our previous finding of reduced striatal DRD2/3 availability in AUD patients compared to individuals at high risk of AUD and HCs (Gleich et al., 2020; Sebold et al., 2019). On the other hand, contrary to our hypothesis we did not find any association between DRD2/ANKK1 TaqIA allele status and striatal DRD2/3 availability, although this result must be interpreted with caution because of the limited effect size and relatively small sample size.

Several studies have reported a link between DRD2/ANKK1 TaqIA allele status (rs1800497) and alcohol-related behaviors (Berggren et al., 2006; Blum et al., 1990, 1991; Mignini et al., 2012; Neiswanger et al., 1995). While DRD2/ANKK1 TaqIA allele status and striatal DRD2/3 availability have been investigated in clinical studies (Comings et al., 1991; Eisenstein et al., 2016; Gluskin \& Mickey, 2016; Savitz et al., 2013) and postmortem samples (Noble et al., 1991; Thompson et al., 1997), ours is the first study to examine DRD2/ANKK1 
TaqIA allele ( $r$ 1800497) and DRD2/3 status in AUD patients in vivo. However, a study in patients with schizophrenia found no association between DRD2 availability and TaqIA allele status by single photon emission computed tomography (Laruelle et al., 1998).

Despite the well-known contribution of dopaminergic impairment to AUD and other substance use disorders (Gleich et al., 2020; Heinz et al., 2005; Martinez et al., 2005; Volkow et al., 1996, 2002, 2007), few studies have examined the relationship between DRD2/3 and genetic predisposing factors in AUD, possibly because of power issues in PET studies, which may also have contributed to the null result in this study. Therefore, our findings are noteworthy as other studies might have experienced similar limitations.

Our study population consisted of 13 AUD patients and $17 \mathrm{HCs}$, which is a typical sample size for PET studies but caused statistical difficulties when calculating allele frequencies in the same sample. Because there were 2 different allele types and hence, 3 genotypes ( $A 1 / A 1, A 1 / A 0$, and $A 0 / A 0)$, the compared groups were relatively small. To minimize the effect of small sample size on the results and because of the lack/very small number of homozygous alleles in the $H C(n=0)$ and AUD $(n=1)$ groups, we pooled A1/A1 and $\mathrm{A} 1 / \mathrm{A} 0$ into a single group. Many other studies have experienced the issue of insufficient data for homozygous alleles, especially in HCs (Eisenstein et al., 2016; M. Hirvonen et al., 2004; M. M. Hirvonen et al., 2009; Laruelle et al., 1998), and have thus been unable to detect betweengroup differences in the effect of DRD2/3 status for the 3 genotypes ofDRD2/ANKK1 TaqIA rs1800497, as was the case in our study. Moreover, even after pooling homozygotes and heterozygotes, the compared subgroups were still relatively small, resulting in power issues in the statistical analyses. One way to overcome this limitation in the future is to pool the results of comparable PET studies with genetic data to increase the sample size.

As the molecular mechanism by which TaqIA allele status influences DRD2 expression is unknown, the functional relevance of any observed associations must be interpreted with caution. Preclinical studies have reported the regulation of ANKK1 expression by dopamine (España-Serrano et al., 2017; Hoenicka et al., 2010), but no direct interaction has been demonstrated thus far.

As described above, low allele frequencies in control subjects may drive associations between DRD2 gene status and AUD (Jung et al., 2019). However, in this study the allele frequency in HCs was comparable to that in AUD patients for the subgroup with no risk allele ( $A-:$ HC, $n=8$ and AUD, $n=7$ ), and was higher in HCs than in AUDs in the risk allele subgroup (A+: HC, $n=10$ and AUD, $n=4)$.

Another factor potentially contributing to our results was the use of ${ }^{18} \mathrm{~F}$-fallypride as the radioligand; this high-affinity DRD2/3 antagonist is nonselective for DRD2 and may be displaced by endogenous dopamine, although the density of DRD3 in the ventral and especially dorsal striatum is relatively low (Searle et al., 2010). Moreover, endogenous dopamine may have influenced data acquisition although there were no stimuli during the scanning and the participants were not actively drinking at the time of the study. The use of specific DRD2 radiotracers such as $\left[{ }^{11} \mathrm{C}\right] \mathrm{NMB}$ may improve the specificity of the results (Eisenstein et al., 2016).

Clarifying the association between DRD2/ANKK1 TaqIA allele status and DRD2/3 availability is important for resolving the longstanding controversy of whether dopaminergic impairment in the striatum of individuals with alcohol dependence is the result of compensatory downregulation or genetic predisposition. To this end, additional investigations that combine data from different PET studies are needed to overcome the issue of low statistical power inherent in this type of research. 


\section{Literature}

Alexandre, M. C. M., Colonetti, T., Bavaresco, D. V., Simon, C. S., Dondossola, E. R., Uggioni, M. L. R., Ferraz, S. D., Rico, E. P., \& da Rosa, M. I. (2019). Evaluation of the dopaminergic system with positron-emission tomography in alcohol abuse: A systematic review. Psychiatry Research, 281, 112542. https://doi.org/10.1016/j.psychres.2019.112542

American Psychiatric Association. (2000). Diagnostic and statistical manual of mental disorders (4th ed., text rev.).

Anton, R. F. (1999). What is craving? Models and implications for treatment. Alcohol Research \& Health: The Journal of the National Institute on Alcohol Abuse and Alcoholism, 23(3), 165-173.

Anton, R. F. (2000). Obsessive-compulsive aspects of craving: Development of the Obsessive Compulsive Drinking Scale. Addiction, 95(8s2), 211-217. https://doi.org/10.1046/j.1360-0443.95.8s2.9.x

Anton, R. F., Moak, D. H., \& Latham, P. (1995). The Obsessive Compulsive Drinking Scale: A self-rated instrument for the quantification of thoughts about alcohol and drinking behavior. Alcoholism, Clinical and Experimental Research, 19(1), 92-99.

Ashburner, J., \& Friston, K. J. (2005). Unified segmentation. NeuroImage, 26(3), 839-851. https://doi.org/10.1016/j.neuroimage.2005.02.018

Beck, A., Wüstenberg, T., Genauck, A., Wrase, J., Schlagenhauf, F., Smolka, M. N., Mann, K., \& Heinz, A. (2012). Effect of Brain Structure, Brain Function, and Brain Connectivity on Relapse in Alcohol-Dependent Patients. Archives of General Psychiatry, 69(8), 842. https://doi.org/10.1001/archgenpsychiatry.2011.2026

Berggren, U., Fahlke, C., Aronsson, E., Karanti, A., Eriksson, M., Blennow, K., Thelle, D., Zetterberg, H., \& Balldin, J. (2006). THE TAQI DRD2 A1 ALLELE IS 
ASSOCIATED WITH ALCOHOL-DEPENDENCE ALTHOUGH ITS EFFECT

SIZE IS SMALL. Alcohol and Alcoholism, 41(5), 479-485.

https://doi.org/10.1093/alcalc/agl043

Blum, K., Noble, E. P., Sheridan, P. J., Finley, O., Montgomery, A., Ritchie, T., Ozkaragoz, T., Fitch, R. J., Sadlack, F., Sheffield, D., Dahlmann, T., Halbardier, S., \& Nogami, H. (1991). Association of the A1 allele of the D2 dopamine receptor gene with severe alcoholism. Alcohol, 8(5), 409-416. https://doi.org/10.1016/0741-8329(91)90693-Q

Blum, K., Noble, E. P., Sheridan, P. J., Montgomery, A., Ritchie, T., Jagadeeswaran, P., Nogami, H., Briggs, A. H., \& Cohn, J. B. (1990). Allelic Association of Human Dopamine D2 Receptor Gene in Alcoholism. JAMA, 263(15), 2055-2060. https://doi.org/10.1001/jama.1990.03440150063027

Comings, D. E., Comings, B. G., Muhleman, D., Dietz, G., Shahbahrami, B., Tast, D., Knell, E., Kocsis, P., Baumgarten, R., \& Kovacs, B. W. (1991). The dopamine D2 receptor locus as a modifying gene in neuropsychiatric disorders. JAMA, 266(13), 1793-1800.

Dick, D. M., \& Bierut, L. J. (2006). The genetics of alcohol dependence. Current Psychiatry Reports, 8(2), 151-157. https://doi.org/10.1007/s11920-006-0015-1

Eisenstein, S. A., Bogdan, R., Love-Gregory, L., Corral-Frías, N. S., Koller, J. M., Black, K. J., Moerlein, S. M., Perlmutter, J. S., Barch, D. M., \& Hershey, T. (2016). Prediction of striatal D2 receptor binding by DRD2/ANKK1 TaqIA allele status. Synapse (New York, N.Y.), 70(10), 418-431. https://doi.org/10.1002/syn.21916

Erritzoe, D., Tziortzi, A., Bargiela, D., Colasanti, A., Searle, G. E., Gunn, R. N., Beaver, J. D., Waldman, A., Nutt, D. J., Bani, M., Merlo-Pich, E., Rabiner, E. A., \& LingfordHughes, A. (2014). In Vivo Imaging of Cerebral Dopamine D3 Receptors in Alcoholism. Neuropsychopharmacology, 39(7), 1703-1712. https://doi.org/10.1038/npp.2014.18 
España-Serrano, L., Guerra Martín-Palanco, N., Montero-Pedrazuela, A., Pérez-Santamarina, E., Vidal, R., García-Consuegra, I., Valdizán, E. M., Pazos, A., Palomo, T., JiménezArriero, M. Á., Guadaño-Ferraz, A., \& Hoenicka, J. (2017). The Addiction-Related Protein ANKK1 is Differentially Expressed During the Cell Cycle in Neural Precursors. Cerebral Cortex, 27(5), 2809-2819. https://doi.org/10.1093/cercor/bhw129

Fehr, C., Yakushev, I., Hohmann, N., Buchholz, H.-G., Landvogt, C., Deckers, H., Eberhardt, A., Kläger, M., Smolka, M. N., Scheurich, A., Dielentheis, T., Schmidt, L. G., Rösch, F., Bartenstein, P., Gründer, G., \& Schreckenberger, M. (2008). Association of Low Striatal Dopamine D 2 Receptor Availability With Nicotine Dependence Similar to That Seen With Other Drugs of Abuse. American Journal of Psychiatry, 165(4), 507514. https://doi.org/10.1176/appi.ajp.2007.07020352

Gleich, T., Spitta, G., Butler, O., Zacharias, K., Aydin, S., Sebold, M., Garbusow, M., Rapp, M., Schubert, F., Buchert, R., Heinz, A., \& Gallinat, J. (2020). Dopamine D2/3 receptor availability in alcohol use disorder and individuals at high risk: Towards a dimensional approach. Addiction Biology, e12915. https://doi.org/10.1111/adb.12915

Gluskin, B. S., \& Mickey, B. J. (2016). Genetic variation and dopamine D2 receptor availability: A systematic review and meta-analysis of human in vivo molecular imaging studies. Translational Psychiatry, 6(3), e747. https://doi.org/10.1038/tp.2016.22

Heinz, A., Siessmeier, T., Wrase, J., Buchholz, H. G., Gründer, G., Kumakura, Y., Cumming, P., Schreckenberger, M., Smolka, M. N., Rösch, F., Mann, K., \& Bartenstein, P. (2005). Correlation of Alcohol Craving With Striatal Dopamine Synthesis Capacity and D2/3 Receptor Availability: A Combined [18F]DOPA and [18F]DMFP PET Study in Detoxified Alcoholic Patients. American Journal of Psychiatry, 162(8), 
1515-1520. https://doi.org/10.1176/appi.ajp.162.8.1515

Heinz, A., Siessmeier, T., Wrase, J., Hermann, D., Klein, S., Grüsser-Sinopoli, S. M., Flor, H., Braus, D. F., Buchholz, H. G., Gründer, G., Schreckenberger, M., Smolka, M. N., Rösch, F., Mann, K., \& Bartenstein, P. (2004). Correlation Between Dopamine D2 Receptors in the Ventral Striatum and Central Processing of Alcohol Cues and Craving. American Journal of Psychiatry, 161(10), 1783-1789. https://doi.org/10.1176/ajp.161.10.1783

Hietala, J., West, C., Syvälahti, E., Någren, K., Lehikoinen, P., Sonninen, P., \& Ruotsalainen, U. (1994). Striatal D2 dopamine receptor binding characteristics in vivo in patients with alcohol dependence. Psychopharmacology, 116(3), 285-290.

Hirvonen, M., Laakso, A., Någren, K., Rinne, J. O., Pohjalainen, T., \& Hietala, J. (2004). C957T polymorphism of the dopamine D2 receptor (DRD2) gene affects striatal DRD2 availability in vivo. Molecular Psychiatry, 9(12), 1060-1061. https://doi.org/10.1038/sj.mp.4001561

Hirvonen, M. M., Laakso, A., Någren, K., Rinne, J. O., Pohjalainen, T., \& Hietala, J. (2009). C957T polymorphism of dopamine D2 receptor gene affects striatal DRD2 in vivo availability by changing the receptor affinity. Synapse (New York, N.Y.), 63(10), 907912. https://doi.org/10.1002/syn.20672

Hoenicka, J., Quiñones-Lombraña, A., España-Serrano, L., Alvira-Botero, X., Kremer, L., Pérez-González, R., Rodríguez-Jiménez, R., Jiménez-Arriero, M. Á., Ponce, G., \& Palomo, T. (2010). The ANKK1 Gene Associated with Addictions Is Expressed in Astroglial Cells and Upregulated by Apomorphine. Biological Psychiatry, 67(1), 311. https://doi.org/10.1016/j.biopsych.2009.08.012

Hua, K., Zhang, J., Wakana, S., Jiang, H., Li, X., Reich, D. S., Calabresi, P. A., Pekar, J. J., van Zijl, P. C. M., \& Mori, S. (2008). Tract Probability Maps in Stereotaxic Spaces: 
Analyses of White Matter Anatomy and Tract-Specific Quantification. NeuroImage, 39(1), 336-347. https://doi.org/10.1016/j.neuroimage.2007.07.053

Innis, R. B., Cunningham, V. J., Delforge, J., Fujita, M., Gjedde, A., Gunn, R. N., Holden, J., Houle, S., Huang, S.-C., Ichise, M., Iida, H., Ito, H., Kimura, Y., Koeppe, R. A., Knudsen, G. M., Knuuti, J., Lammertsma, A. A., Laruelle, M., Logan, J., ... Carson, R. E. (2007). Consensus Nomenclature for in vivo Imaging of Reversibly Binding Radioligands. Journal of Cerebral Blood Flow \& Metabolism, 27(9), 1533-1539. https://doi.org/10.1038/sj.jcbfm.9600493

Ishibashi, K., Robertson, C. L., Mandelkern, M. A., Morgan, A. T., \& London, E. D. (2013). The Simplified Reference Tissue Model with 18F-fallypride PET: Choice of Reference Region. Molecular Imaging, 12(8). http://www.ncbi.nlm.nih.gov/pmc/articles/PMC4103900/

Jacobi, F., Mack, S., Gerschler, A., Scholl, L., Höfler, M., Siegert, J., Bürkner, A., Preiss, S., Spitzer, K., Busch, M., Hapke, U., Gaebel, W., Maier, W., Wagner, M., Zielasek, J., \& Wittchen, H.-U. (2013). The design and methods of the mental health module in the German Health Interview and Examination Survey for Adults (DEGS1-MH). International Journal of Methods in Psychiatric Research, 22(2), 83-99. https://doi.org/10.1002/mpr.1387

Jung, Y., Montel, R. A., Shen, P.-H., Mash, D. C., \& Goldman, D. (2019). Assessment of the Association of D2 Dopamine Receptor Gene and Reported Allele Frequencies With Alcohol Use Disorders. JAMA Network Open, 2(11). https://doi.org/10.1001/jamanetworkopen.2019.14940

Kamp, F., Proebstl, L., Penzel, N., Adorjan, K., Ilankovic, A., Pogarell, O., Koller, G., Soyka, M., Falkai, P., Koutsouleris, N., \& Kambeitz, J. (2018). Effects of sedative drug use on the dopamine system: A systematic review and meta-analysis of in vivo 
neuroimaging studies. Neuropsychopharmacology, 1. https://doi.org/10.1038/s41386018-0191-9

Kivlahan, D. R., Sher, K. J., \& Donovan, D. M. (1989). The Alcohol Dependence Scale. 50(2), 170-175. https://doi.org/10.15288/jsa.1989.50.170

Laruelle, M., Gelernter, J., \& Innis, R. B. (1998). D 2 receptors binding potential is not affected by Taq1 polymorphism at the D 2 receptor gene. Molecular Psychiatry, 3(3), 261-265. https://doi.org/10.1038/sj.mp.4000343

Martinez, D., Gil, R., Slifstein, M., Hwang, D.-R., Huang, Y., Perez, A., Kegeles, L., Talbot, P., Evans, S., Krystal, J., Laruelle, M., \& Abi-Dargham, A. (2005). Alcohol dependence is associated with blunted dopamine transmission in the ventral striatum. Biological Psychiatry, 58(10), 779-786. https://doi.org/10.1016/j.biopsych.2005.04.044

Martinez, D., Slifstein, M., Broft, A., Mawlawi, O., Hwang, D.-R., Huang, Y., Cooper, T., Kegeles, L., Zarahn, E., Abi-Dargham, A., Haber, S. N., \& Laruelle, M. (2003). Imaging human mesolimbic dopamine transmission with positron emission tomography. Part II: Amphetamine-induced dopamine release in the functional subdivisions of the striatum. Journal of Cerebral Blood Flow and Metabolism: Official Journal of the International Society of Cerebral Blood Flow and Metabolism, 23(3), 285-300. https://doi.org/10.1097/01.WCB.0000048520.34839.1A

Mawlawi, O., Martinez, D., Slifstein, M., Broft, A., Chatterjee, R., Hwang, D.-R., Huang, Y., Simpson, N., Ngo, K., Van Heertum, R., \& Laruelle, M. (2001). Imaging Human Mesolimbic Dopamine Transmission with Positron Emission Tomography: I. Accuracy and Precision of D2 Receptor Parameter Measurements in Ventral Striatum. Journal of Cerebral Blood Flow \& Metabolism, 21(9), 1034-1057. https://doi.org/10.1097/00004647-200109000-00002 
Mignini, F., Napolioni, V., Codazzo, C., Carpi, F. M., Vitali, M., Romeo, M., \& Ceccanti, M. (2012). DRD2/ANKK1 TaqIA and SLC6A3 VNTR polymorphisms in alcohol dependence: Association and gene-gene interaction study in a population of Central Italy. Neuroscience Letters, 522(2), 103-107. https://doi.org/10.1016/j.neulet.2012.06.008

Mukherjee, J., Yang, Z.-Y., Das, M. K., \& Brown, T. (1995). Fluorinated benzamide neuroleptics-III. Development of (S)-N-[(1-allyl-2-pyrrolidinyl)methyl]-5-(3[18F]fluoropropyl)-2,3-dimethoxybenzamide as an improved dopamine D-2 receptor tracer. Nuclear Medicine and Biology, 22(3), 283-296. https://doi.org/10.1016/09698051(94)00117-3

Neiswanger, K., Hill, S. Y., \& Kaplan, B. B. (1995). Association and linkage studies of the TAQI A1 allele at the dopamine D2 receptor gene in samples of female and male alcoholics. American Journal of Medical Genetics, 60(4), 267-271. https://doi.org/10.1002/ajmg.1320600402

Noble, E. P., Blum, K., Ritchie, T., Montgomery, A., \& Sheridan, P. J. (1991). Allelic Association of the D2 Dopamine Receptor Gene With Receptor-Binding Characteristics in Alcoholism or Gene ism. Archives of General Psychiatry, 48(7), 648-654. https://doi.org/10.1001/archpsyc.1991.01810310066012

Rominger, A., Cumming, P., Xiong, G., Koller, G., Böning, G., Wulff, M., Zwergal, A., Förster, S., Reilhac, A., Munk, O., Soyka, M., Wängler, B., Bartenstein, P., la Fougère, C., \& Pogarell, O. (2012). [18F]Fallypride PET measurement of striatal and extrastriatal dopamine D 2/3 receptor availability in recently abstinent alcoholics. Addiction Biology, 17(2), 490-503. https://doi.org/10.1111/j.1369-1600.2011.00355.x

Savitz, J., Hodgkinson, C. A., Martin-Soelch, C., Shen, P.-H., Szczepanik, J., Nugent, A. C., Herscovitch, P., Grace, A. A., Goldman, D., \& Drevets, W. C. (2013). 
DRD2/ANKK1 Taq1A polymorphism (rs1800497) has opposing effects on D2/3 receptor binding in healthy controls and patients with major depressive disorder. The International Journal of Neuropsychopharmacology / Official Scientific Journal of the Collegium Internationale Neuropsychopharmacologicum (CINP), 16(9), 20952101. https://doi.org/10.1017/S146114571300045X

Searle, G., Beaver, J. D., Comley, R. A., Bani, M., Tziortzi, A., Slifstein, M., Mugnaini, M., Griffante, C., Wilson, A. A., Merlo-Pich, E., Houle, S., Gunn, R., Rabiner, E. A., \& Laruelle, M. (2010). Imaging dopamine D3 receptors in the human brain with positron emission tomography, [11C]PHNO, and a selective D3 receptor antagonist. Biological Psychiatry, 68(4), 392-399. https://doi.org/10.1016/j.biopsych.2010.04.038

Sebold, M., Spitta, G., Gleich, T., Dembler-Stamm, T., Butler, O., Zacharias, K., Aydin, S., Garbusow, M., Rapp, M., Schubert, F., Buchert, R., Gallinat, J., \& Heinz, A. (2019). Stressful life events are associated with striatal dopamine receptor availability in alcohol dependence. Journal of Neural Transmission (Vienna, Austria: 1996), 126(9), 1127-1134. https://doi.org/10.1007/s00702-019-01985-2

Slifstein, M., Hwang, D.-R., Huang, Y., Guo, N., Sudo, Y., Narendran, R., Talbot, P., \& Laruelle, M. (2004). In vivo affinity of [18F]fallypride for striatal and extrastriatal dopamine D2 receptors in nonhuman primates. Psychopharmacology, 175(3), 274286. https://doi.org/10.1007/s00213-004-1830-x

Statistical Parametric Mapping (SPM) (8th version). (2017). [Computer software]. Wellcome Department of Imaging Neuroscience, Institute of Neurology. http://www.fil.ion.ucl.ac.uk/spm/

Sullivan, J. T., Sykora, K., Schneiderman, J., Naranjo, C. A., \& Sellers, E. M. (1989). Assessment of Alcohol Withdrawal: The revised clinical institute withdrawal 
assessment for alcohol scale (CIWA-Ar). British Journal of Addiction, 84(11), 13531357. https://doi.org/10.1111/j.1360-0443.1989.tb00737.x

Surti, S., Kuhn, A., Werner, M. E., Perkins, A. E., Kolthammer, J., \& Karp, J. S. (2007). Performance of Philips Gemini TF PET/CT scanner with special consideration for its time-of-flight imaging capabilities. Journal of Nuclear Medicine: Official Publication, Society of Nuclear Medicine, 48(3), 471-480.

Thompson, J., Thomas, N., Singleton, A., Piggott, M., Lloyd, S., Perry, E. K., Morris, C. M., Perry, R. H., Ferrier, I. N., \& Court, J. A. (1997). D2 dopamine receptor gene (DRD2) Taq1 A polymorphism: Reduced dopamine D2 receptor binding in the human striatum associated with the A1 allele. Pharmacogenetics, 7(6), 479-484. https://doi.org/10.1097/00008571-199712000-00006

Volkow, N. D., Wang, G.-J., Fowler, J. S., Logan, J., Hitzemann, R., Ding, Y.-S., Pappas, N., Shea, C., \& Piscani, K. (1996). Decreases in Dopamine Receptors but not in Dopamine Transporters in Alcoholics. Alcoholism: Clinical and Experimental Research, 20(9), 1594-1598. https://doi.org/10.1111/j.1530-0277.1996.tb05936.x

Volkow, N. D., Wang, G.-J., Maynard, L., Fowler, J. S., Jayne, B., Telang, F., Logan, J., Ding, Y.-S., Gatley, S. J., Hitzemann, R., Wong, C., \& Pappas, N. (2002). Effects of alcohol detoxification on dopamine D2 receptors in alcoholics: A preliminary study. Psychiatry Research, 116(3), 163-172.

Volkow, N. D., Wang, G.-J., Telang, F., Fowler, J. S., Logan, J., Jayne, M., Ma, Y., Pradhan, K., \& Wong, C. (2007). Profound decreases in dopamine release in striatum in detoxified alcoholics: Possible orbitofrontal involvement. The Journal of Neuroscience: The Official Journal of the Society for Neuroscience, 27(46), 1270012706. https://doi.org/10.1523/JNEUROSCI.3371-07.2007

Wittchen, H. U., Lachner, G., Wunderlich, U., \& Pfister, H. (1998). Test-retest reliability of 
the computerized DSM-IV version of the Munich-Composite International Diagnostic Interview (M-CIDI). Social Psychiatry and Psychiatric Epidemiology, 33(11), 568578.

Wu, Y., \& Carson, R. E. (2002). Noise Reduction in the Simplified Reference Tissue Model for Neuroreceptor Functional Imaging. Journal of Cerebral Blood Flow \& Metabolism, 22(12), 1440-1452.

https://doi.org/10.1097/01.WCB.0000033967.83623.34 


\section{Funding}

This work was supported by the German Research Foundation (Deutsche Forschungsgemeinschaft, FOR 1617: grants FR 3572/1-1, WA 1539/7-1, HE 2597/14-1, HE 2597/15-1, HE 2597/14 -2, HE 2597/15-2, GA 707/6-1, RA 1047/2-1, and RA 1047/2-2). D. Med. D. Phil. Eva Friedel is a participant in the BIH-Charité Clinician Scientist Program funded by the Charité-Universitätsmedizin Berlin and Berlin Institute of Health.

\section{Conflict of interest}

The authors declare that the research was conducted in the absence of any commercial or financial relationships that could be construed as a potential conflict of interest.

\section{Transparency Statement}

This report is an exhaustive report on all data available from the research project relating to the topic, where at least one of the authors was principal investigator ( $\mathrm{AH}, J G$ and EF). This includes not only null findings, or unexpected findings, but also studies that are suspected to have failed, with careful explanation of the circumstances of the failure (e.g., experimental error, failed manipulation check). The context surrounding how these data were collected, and if they are somehow connected to already published studies (e.g., dropped experiments) is carefully explained.

\section{Author Contributions}

GS, JG, TG, MS and EF conceived the study; GS, EF, LF, JG, AH, MS, TG, TZ and RB drafted the manuscript; GS, EF, LF, TZ, TG and RB analyzed and interpreted the data; LF created the figures; EF and JG supervised the study; and TZ, AH, TG, RB, AH and MS revised the manuscript for important intellectual content. All authors contributed to manuscript revision, and read and approved the submitted version.

\section{Abbreviations}

AIC, Akaike information criterion

ANKK1, ankyrin repeat and kinase domain-containing 1

AUD, alcohol use disorder

BIC, Bayesian information criterion

$\mathrm{BP}_{\mathrm{ND}}$, non-displaceable binding potential

CIDI, Composite International Diagnostic Interview

DRD2/3, dopamine D2/3 receptor

DSM-IV, Diagnostic and Statistical Manual for Mental Disorders, 4th Edition

$\mathrm{HC}$, healthy control

MNI, Montreal Neurological Institute

$\mathrm{MRI}$, magnetic resonance imaging

PET, positron emission tomography 
SNP, single nucleotide polymorphism 